\title{
COLLABORATION: REFLECTIONS ON AN ACADEMIC CAREER
}

\author{
Kathie Lasater
}

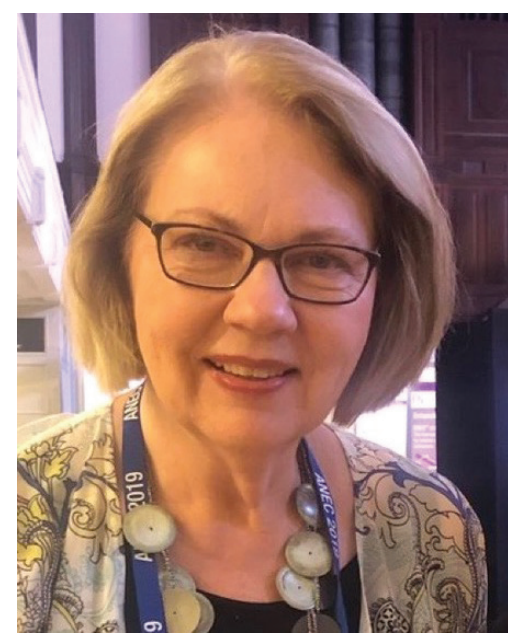

Figure I. Kathie Lasater at ANEC conference in Dunedin, New Zealand, 2019. Source:

Conference organisers (with permission)

\section{INTRODUCTION}

One recently retired nurse educator reflects on the role of collaboration in her academic career, especially in developing an innovative curriculum and a programme of research. The paper traces the author's experiences over time and how an academic career can be cultivated through collaborations, some planned and some unplanned. The paper culminates in seven lessons learned about collaboration the author is passing along as a result of her experiences.

After nearly 50 years in nursing practice and academia, I am still a registered nurse but in voluntary roles. In the year following my retirement from employment, I have had the opportunity to look back - reflect - and appreciate the role that collaboration has had in the development of my professional academic career, both in curriculum development and research. Why is this important enough to write about and why, you may wonder, should you bother to read it? The short answer is that we can learn from and be mentored by others' experiences. During the academic year when we are busy providing quality education for our students,

there is little time for much else, including mentorship and reflection. It is only since I retired and have given two presentations about the development of my research career that I have recognized the key role of collaboration.

Officially, to collaborate means, "to work jointly with others or together especially in an intellectual endeavor" (https://www.merriam-webster.com/dictionary/collaborate). As educators, we expend so much effort to help our students grasp the critical importance of teamwork in patient care. As academics, however, it is not uncommon to experience some isolation, and many of us would rather work alone than try to collaborate with other individuals to produce something of value. Working with others can be messy, time-consuming, and result in frustration, especially when collaborators have different work styles, expectations, or priorities. Additionally, individual schedules are often not conducive to collaboration, either locally or internationally. For the sake of this paper, I will briefly describe what I have learned from collaborating on a momentous curriculum development project, but the primary purpose will be to describe some ways in which my research programme and academic reputation have been furthered through collaboration. 


\section{COLLABORATING TO DEVELOP A SHARED CURRICULUM}

During my doctoral studies in education while teaching nursing full time, an opportunity arose to be part of a curriculum development team that involved educators from an entire state in the United States (US), the one in which I was employed. About II programmes of nursing sent representatives to develop a shared curriculum. The primary idea behind the shared curriculum was that students who were geographically isolated from the five campuses of the public baccalaureate programmel could begin their studies in two-year, associate degree programmes ${ }^{2}$, and finish their baccalaureate degrees with an extra year in the public university programme, making nursing education at that level more available and inclusive. The extra year could be done online or on a campus of the public university.

About 40 representatives from associate degree programmes and the five campuses of the public baccalaureate programme came from around the state for one and a half days per month for more than two years. We approached the project with a shared purpose and agreement about no dominance of a programme or type of programme over another. Most of us did not know each other before this experience so taking time for meeting and greeting as well as having fun throughout the process enhanced the relationships and allowed us to learn to trust each other and the group to create and implement the project. Leadership was eventually shared between an educator from the public university and one from an associate degree programme. Expert leadership and enough funding to support the effort were catalysts for collaboration (Tanner et al., 2008).

The collaboration among representatives from member programmes endures, more than 10 years later, through an annual statewide retreat and continued shared leadership (Gubrud-Howe et al., 2017). The retreat allows time for reviewing curricular and course outcomes, refining the courses and assessment strategies, as well as bringing new educators into the collaboration. Having a shared curriculum means that academic calendars, outcomes, and language among programmes are similar. How the shared outcomes are met is the purview of each programme. Personal lessons learned included how critical it was/is to have all stakeholders equally involved in the process and to clarify the principles and outcomes of a curriculum right from the beginning. These were valuable lessons at a crucial time in my development as an academic. I believed (and still do) that anything was possible with collaboration just as I was completing my doctoral degree in education!

\section{COLLABORATING TO BUILD A PROGRAMME OF RESEARCH}

\section{Getting started}

Of course, original research is most often a requirement of doctoral study. Generally, it is not an occasion for collaboration except, crucially, with one's committee. However, once complete, the dissemination process begins, along with potential for broader collaboration to build a programme of research. One of my dissertation research outcomes was an evidence-based rubric for assisting educators to put into words the developmental process for individual students to learn to make clinical judgments (Lasater, 2007; Tanner, 2006), particularly through the use of high fidelity simulation. My collaborators in the curriculum development project knew about the rubric and began to talk about it amongst themselves as well as at conferences or during consultations. At the time, I found it surprising that other educators had some of the same needs as I, but it set the stage for future collaborations. The

I Public baccalaureate programme: such a university in the US is owned and managed by an individual state and/or receives national funding whereas private universities are funded by their own endowments. Both public and private universities generally charge students tuition with private universities requiring higher rates.

2 Associate degree programme: a US academic programme usually undertaken for two to three years at the undergraduate level after secondary school. Associate nursing degree graduates can become registered nurses after successfully passing the nursing licensing examination in the US. Associate degree graduates can subsequently enroll in a baccalaureate programme to complete their degrees. 
rubric was officially adopted to support one of the new shared curriculum's outcomes, and upon completion of my degree, I immediately submitted five abstracts, four of which were accepted for presentations at major diverse conferences in the following year. The end result was an audience primed and ready for the subsequent publication of the rubric and the evidence-based process that facilitated its creation. Within a year, three individuals who knew about the rubric asked for permission to validate the rubric in their doctoral studies (Adamson et al., 20I2), inviting my collaboration in a variety of ways. For example, all asked permission to use the rubric for their studies, one asked me to train raters, the others asked only for periodic consultations.

Two years after the publication of the rubric, one researcher from my university was presenting at an international conference when we were approached by a group from a large university in a different geographic area of the US. They invited us to give a presentation on their campus about clinical judgment development, using high fidelity simulation, for their faculty. Based on our connection at that point, they applied for a national education grant to do a collaborative study to determine if high fidelity simulation differentiated levels of clinical judgment, using the rubric as a rating tool. This quasi-experimental study was implemented, collaborating with two other US programmes that I knew of, and an international programme with which the other university had an ongoing relationship $(\mathrm{N}=275)$. The resulting dissemination further enhanced and expanded knowledge about the development of clinical judgment (Johnson et al., 2012; Lasater et al., 2014). In addition, we were among the first groups to use and write about the digital tools required to collaborate in international research, such as following protocols and reporting data (Lasater et al., 20I2). What I realised at this point was that my work would never become wellknown without collaboration as a bridge to dissemination and the next research project(s). , I learned that such transitions are a critical time to highlight changes and measure effectiveness in teaching and learning. They are also busy times so finding collaborators can be challenging.

\section{Looking for international impact}

Several years after the rubric's publication, I made the decision to go forward for promotion to professor. However, the missing element was evidence of international impact so I sent an abstract to an international nursing education conference in Sydney, Australia. At the same time, my mentor was invited to present there at a regional simulation conference following the larger conference. Once my initial abstract had been accepted, I reached out to the organiser of the regional conference to offer to present, which seemed very forward at the time. She graciously invited me to present and at both conferences, networking was a key feature of which I took full advantage. Although I did not return home with a solid plan for research, I met a number of potential collaborators, many of whom later became co-investigators. I was also asked to write a manuscript about my presentation for a special journal edition (Lasater, 20II) and serve on an international journal advisory board that was looking for more US exposure. This position later evolved into an assistant editor role for another highly-ranked nursing education journal. The board and editor roles have brought me contact with international researchers, many of whom I have had opportunities to collaborate. Meanwhile, ideas for future studies were "stewing," but there was no product to show for it. During this time, I was approaching traditional retirement age and began to wonder if that was my next step.

\section{Expanding beyond students}

At about this time, the primary educator at the hospital associated with my university approached me and the colleague who most resonated with the clinical judgment rubric. The educator wanted to adapt the rubric for use as an assessment tool for newly hired nurses, required by a US hospital accreditation group. This accreditor expected that hospitals assess competence to practise in order to facilitate orientation and onboarding of nurses. The educator considered the rubric a tool that she, the hospital educators, and preceptors of new hires could use to tailor those onboarding strategies for newly hired nurses (Lasater et al., 2015; Nielsen et al., 2016). Through our 
collaboration with the hospital, I had an important and surprising realisation: the rubric had relevance for graduate and practising nurses as well as students. This insight brought me into contact with collaborators beyond academe and extended my clinical judgment research and career.

\section{Expanding across the US}

From the time of the rubric's publication, I received numerous requests for permission to use it for research, curriculum development, and simulation assessment. Intuitively, I had put my copyright on the publication of the rubric so I maintained ownership of the rubric rather than the journal that published it. As a result, I received two or more requests per week for at least 10 years post-publication, in other words, hundreds of them. It was a tremendous advantage for me to serve as a clearinghouse because I could guide people to use the rubric or point them toward another tool that measured what they were interested in, and I also knew how the rubric was being used. These colleagues' creativity encouraged my own and also helped me to listen for future collaborators. Some became longer-term colleagues with whom I collaborated and with whom I am still in contact. As they used the rubric and reported their findings, the rubric and my name became more well-known, even outside the US.

Within the US, the National Council for State Boards of Nursing (n.d.) is "an independent, not-for-profit organization through which nursing regulatory bodies act and counsel together on matters of common interest and concern affecting public health, safety and welfare, including the development of nursing licensure examinations." They also develop the US licensure examination and recently recognized that it needs to better assess new graduates' clinical judgment. Several years ago, they contacted me to collaborate with them to bridge the gap between the science of measurement required to revise the examination and nurse educators as they prepare students for practice. The outcome was a publication (Dickison et al., 2019), and further national research involving four of my clinical judgment collaborators is underway.

\section{International collaboration}

As familiarity with the rubric grew, I began to hear from graduate students and faculty around the world, seeking permission to translate the rubric into other languages, using scholarly approaches involving back translations. Of the now 16 other languages either completed or in process, I have collaborated with eight of these groups to help them nuance meanings of phrases, read back translations, or generally consult. Some of the translations have involved face-to-face collaborations and some publications.

By far, the most international collaboration of my career occurred by leading a very large $(\mathrm{N}=532)$ study, involving nursing education students in Australia, New Zealand, and the US. Colleagues in Australia and New Zealand, whom I came to know around 2010, collaborated in the design and implementation of a study examining the impact of students' backgrounds on the development of their clinical judgment. Through a collaborative process, we were able to control for a variety of variables as well as explore the impact of them. Six researchers (two from each country) participated, including anonymously coding some data. Due to the complexity of the project, the time from design to publication was about five years with data collection approximately in the middle of that timeframe (Lasater et al., 2019; Kelly et al., 2020).

Through networking at an international conference in 2014, I met two critical collaborators and later, had the opportunity to apply for and be awarded a prestigious Fulbright Scholar Research Award. Our work focused on population health, a subject I taught for all of my academic career. We initially met over a very informal lunch, talking about our respective work and identifying areas we thought overlapped. This was followed by their visit to my university and an expanding collaboration with two nurse educators from another US university. Together, we wrote a persuasive paper which was published in a highly regarded nursing education journal (Atherton et al., 2017). When the prospect arose to apply for a Fulbright Scholar Research Award, my collaborators embraced the 
opportunity and helped me develop a cogent and cutting-edge proposal in two weeks' time to meet the deadline. During four months of working together onsite in Scotland, we also collaborated with a master's intern from The Netherlands. From the Fulbright award, there have been multiple presentations and three publications to date (Lasater et al., 2019; Lasater et al., 2020; Scheffer et al., 2019) with a fourth paper in process.

\section{LESSONS LEARNED ABOUT COLLABORATION}

From my retrospective vantage, I realise a review of my career has highlighted some important lessons. Some part of my career trajectory was timing, but I can see that collaborations were as important if not more so. I offer the following advice for maximising collaboration to advance one's reputation and scholarly work:

I. Practise verbally summarising your scholarly interests so you can easily share them;

2. Attend and submit abstracts for presentation at scientific conferences that focus on or highlight your academic interests;

3. Keep an open mind; you really do not know what might lay ahead;

4. Introduce yourself to conference presenters or attendees who have similar academic interests;

5. Disseminate through publications as well as presentations;

6. Learn the art of collaboratively writing for publication (Clark, 2014);

7. Risk offering to present your work at conferences or universities where you have colleagues or may be visiting.

\section{CONCLUSION}

Reflection in retirement offered the opportunity to examine an academic career over a period of two decades. Reflection revealed that collaboration advanced an academic career, especially through curriculum development and research. It is not always easy to work with others; however, the rewards for patience, setting goals, and encouraging/mentoring others have been worth it for this author.

Postscript: During the upsurge of the 2020 pandemic, one of the unanticipated benefits of international collaboration over the previous decade was to share personal as well as professional connections with colleagues around the globe, to learn how they coped with the threat and challenges, and to wish them, their colleagues, and their loved ones the best for their health and safekeeping.

Kathie Lasater (ㅁ0002-4834-6460) EdD, RN, ANEF, FAAN, Professor Emerita is known for creating the Lasater Clinical Judgment Rubric, an evidence-based assessment tool. In 2018, Kathie was a Fulbright Visiting Scholar, exploring how UK nursing leaders envision the role of nursing in improving population outcomes and a deepening emphasis on social determinants of health.

Correspondence to: Kathie Lasater: Oregon Health \& Science University, 2443 N 3rd St, Washougal, WA, 9867I USA; Email: lasaterk@ohsu.edu 


\section{REFERENCES}

Adamson, K. A., Gubrud-Howe, P., Sideras, S., \& Lasater, K. (2012). Assessing the inter-rater reliability of the Lasater Clinical Judgment Rubric: Three strategies. Journal of Nursing Education 5I(2), 66-73. https://doi.org/I0.3928/0 I484834-20 IIII30-03

Atherton, I. M., Lasater, K., Richards, L., Mathews, L. R., Simpson, V., \& Kyle, R. (2017). Population health and nurse education time to step-up. Nurse Education Today, 51, II7-119. https://doi.org/I0.1016/j.nedt.2016.08.002.

Benner, P., Sutphen, M., Leonard, V., \& Day, L. (2010). Educating nurses: A call for radical transformation. Stanford, CA: Jossey-Bass.

Clark, C. (2014). A formula for collaborative writing. Journal of Nursing Education, 53(3), I19-120.

Dickison, P., Haerling, K. A. \& Lasater, K. (2019). The National Council of State Boards of Nursing Clinical Judgment Model. Journal of Nursing Education, 58(2), 72-78. https://doi.org/I0.3928/0I484834-20190122-03

Gubrud, P., Spencer, A., \& Wagner, L. (2017). From start-up to sustainability: A decade of collaboration to shape the future of nursing. Nursing Education Perspectives, 38(5), 225-232. https://doi.org/I0.1097/01.NEP. 0000000000000212

Institute of Medicine. (2010). The future of nursing: Leading change, advancing health. National Academies Press. https://www.ncbi. nlm.nih.gov/books/NBK209880/

Johnson, E., Lasater, K., Hodson Carlton, K., Sideras, S., Siktberg, L., \& Dillard, N. (20I2). Geriatrics in simulation: Role modeling and clinical judgment effect. Nursing Education Perspectives, 33(3), 176-180.

Kelly, M., Lapkin, S., McGrath, B., Holloway, K., Nielsen, A., Stoyles, S., Campbell, M., Dieckmann, N., F., \& Lasater, K. (2020). Modeling practice for clinical judgment: A multi-site audio-visual simulation evaluation. Clinical Simulation in Nursing, 43, I016. https//doi.org/https://doi.org//0//016/j.ecns.2020.08.006

Lasater, K. (2007). Clinical judgment development: Using simulation to create an assessment rubric. Journal of Nursing Education, 46, 496-503.

Lasater, K. (20II). Clinical judgment: The last frontier for evaluation. Nurse Education in Practice, II(2), 86-92. https//doi. org/0.1016/j.nepr.2010.11.013

Lasater, K., Atherton, I. M., \& Kyle, R. G. (2020). Population health as a 'platform' for nurse education: A qualitative study of nursing leaders. Nurse Education Today, 86, 1-7. https//doi.org/10.1016/.nedt.2019.104313.

Lasater, K., Holloway, K., Lapkin, S., Kelly, M., McGrath, B., Nielsen, A., Stoyles, S., Dieckmann, N. F., \& Campbell, M. (2019). Do preregistration nursing students' backgrounds impact what they notice and interpret about patients? Nurse Education Today, 78, 37-43. https//doi.org/10.1016/j.nedt.2019/03/013

Lasater, K., Johnson, E., Hodson Carlton, K., Siktberg, L., \& Sideras, S. (2012). A digital toolkit to implement and manage a multisite study. Journal of Nursing Education, 5I(3), 127-132. https//doi.org/I0.3928/0 I484834-201201I3-02

Lasater, K., Johnson, E. A., Ravert, P., \& Rink, D. (2014). Role-modeling clinical judgment in an older adult simulation. Journal of Nursing Education, 53(5), 257-264. https//doi.org/I0.3928/0I484834-201404I4-0 I

Lasater, K., Kyle, R. G., \& Atherton, I. M. (2019). Zooming out to prioritise population health in nurse education [Editorial]. Collegian, 26(5), 51I-513. https://doi.org/10.1016/j.colegn.2019.09.007

Lasater, K., Nielsen, A., Stock, M., \& Ostrogorsky, T. (2015). Evaluating clinical judgment of newly hired staff nurses. Journal of Continuing Education in Nursing, 46(I2), 563-57I. https//doi.org/l0.3928/00220124-20151II2-09

National Council of State Boards of Nursing. (n.d.). The world leader in nursing regulatory knowledge. Retrieved from https://www. ncsbn.org/index.htm

Scheffer, M. M. J., Lasater, K., Atherton, I. M., \& Kyle, R. G. (2019). Student nurses' attitudes to social justice and poverty: An international comparison. Nurse Education Today, 80, 59-66. https://doi.org/l0.1016/j.nedt.2019.06.007

Tanner, C. A. (2006). Thinking like a nurse: A research-based model of clinical judgment. Journal of Nursing Education, 45(6), 204-211.

Tanner, C. A., Gubrud-Howe, P. \& Shores, L. (2008). The Oregon Consortium for Nursing Education: A response to the nursing shortage. Policy, Politics, and Nursing Practice, 9(3), 203-209. https//doi.org//0.1 I77/I527/54408323043 